\title{
Anesthetic management of a parturient with hypermobility phenotype but possible vascular genotype Ehlers-Danlos syndrome
}

\section{Gestion anesthésique d'une parturiente ayant un phénotype d'hypermobilité, mais un génotype vasculaire possible de syndrome d'Ehlers-Danlos}

\author{
Kelly Fedoruk, MD • Karen Chong, MD, PhD - Mathew Sermer, MD • \\ Jose C. A. Carvalho, MD, PhD \\ Received: 15 April 2015/Revised: 2 August 2015/Accepted: 1 September 2015/Published online: 14 September 2015 \\ (C) Canadian Anesthesiologists' Society 2015
}

\begin{abstract}
Purpose We describe a case of a term parturient previously clinically diagnosed with hypermobility type Ehlers-Danlos syndrome (EDS) but later diagnosed with a genotype that may be associated with vascular type EDS. Clinical features This 26-yr-old primigravida had been clinically diagnosed with hypermobility type EDS prior to her pregnancy. Nevertheless, subsequent genetic testing during pregnancy revealed a heterozygous variant of unknown significance in the COL3Al gene causative for vascular type EDS. A multidisciplinary decision was made to prioritize the phenotype rather than the genotype in regard to clinical management of labour. An induced labour was planned with instrument-assisted vaginal delivery. We elected to proceed with placement of an epidural catheter for provision of labour analgesia and
\end{abstract}

\footnotetext{
Author contributions Kelly Fedoruk and Jose C.A. Carvalho cared for the patient and wrote and revised the manuscript. Karen Chong and Mathew Sermer cared for the patient and revised the manuscript.
}

K. Fedoruk, MD · J. C. A. Carvalho, MD, PhD (ه)

Department of Anesthesia and Pain Management, Mount Sinai

Hospital, 600 University Avenue, Room 19-103, Toronto,

ON M5G 1X5, Canada

e-mail: jose.carvalho@uhn.ca

K. Chong, MD, PhD

The Prenatal Diagnosis and Medical Genetics Program, Department of Obstetrics and Gynecology, Mount Sinai Hospital, University of Toronto, Toronto, Canada

M. Sermer, MD - J. C. A. Carvalho, MD, PhD Department of Obstetrics and Gynecology, Mount Sinai Hospital, University of Toronto, Toronto, ON, Canada anesthesia during delivery. Both maternal and neonatal outcomes were excellent.

Conclusion The risk of severe morbidity and mortality in parturients with vascular EDS has warranted recommendations for modified management of labour, particularly regarding mode and timing of delivery. Nevertheless, a multidisciplinary approach and consideration of phenotype rather than genotype alone were instrumental in the successful management of this patient. Genetic testing of patients who display features of EDS and/or who have a positive family history of the disease is important in the preparation for labour and delivery. In the absence of convincing signs of vascular EDS and a negative family history, it may be rational to offer certain parturients neuraxial anesthesia and a trial of vaginal labour.

\section{Résumé}

Objectif Nous décrivons un cas de parturiente à terme chez laquelle un diagnostic clinique de syndrome d'Ehlers-Danlos (EDS) de type hypermobilité a été fait, mais dont le diagnostic génotypique ultérieur pouvait être associé à un EDS de type vasculaire.

Caractéristiques cliniques Cette patiente de 26 ans, primigeste, avait reçu un diagnostic clinique d'EDS de type hypermobilité avant sa grossesse. Néanmoins, des tests génétiques ultérieurs effectués pendant la grossesse ont révélé un variant hétérozygote de signification inconnue du gène COL3Al en cause dans l'EDS de type vasculaire. Une décision multidisciplinaire de privilégier le phénotype plutôt que le génotype a été prise concernant la gestion clinique du travail. Le déclenchement $d u$ travail a été planifié avec accouchement par voie 
vaginale et aide instrumentale. Nous avons choisi de mettre en place un cathéter péridural pour assurer une analgésie du travail et l'anesthésie pendant l'accouchement. Les résultats ont été excellents pour la mère et pour l'enfant.

Conclusion Le risque de morbidité sévère et de mortalité chez les parturientes présentant un EDS vasculaire a justifié des recommandations de modifications de la gestion du travail, notamment pour ce qui concerne le mode et la date de l'accouchement. Néanmoins, une démarche multidisciplinaire et la prise en compte du phénotype plutôt que du génotype seul ont joué un rôle décisif pour la réussite de la prise en charge de cette patiente. Les tests génétiques chez des patients présentant des caractéristiques d'EDS et/ou qui ont des antécédents familiaux de la maladie sont importants dans la préparation du travail et de l'accouchement. En l'absence de signes convaincants d'EDS vasculaire et d'antécédents familiaux, il peut être rationnel de proposer à certaines parturientes une anesthésie neuraxiale et un essai de travail et d'accouchement par voie vaginale.

Ehlers-Danlos syndrome (EDS) is a heterogeneous disease characterized by varying types and severity of tissue dysfunction secondary to abnormal collagen production. ${ }^{1}$ The classification of EDS has been revised multiple times in past decades. The most recent nosology, known as the Villefranche classification, considers the biochemical and molecular basis of disease along with clinical manifestations in the categorization of syndrome subtype. Currently, six major subtypes of EDS are recognized, each containing their own respective major and minor diagnostic criteria. ${ }^{1}$ Nevertheless, there appears to be a growing database of families exhibiting non-classical and even conflicting genotypic and phenotypic diagnoses of hypermobility and vascular type $\mathrm{EDS}^{2,3}$ which challenges the most recent classification system.

Each subtype of this rare connective tissue disorder can pose a multitude of challenges for the anesthetic and obstetrical management of pregnant women delivering vaginally or via Cesarean delivery. In general, all types of EDS predispose the affected women to pelvic pain, hypermobility, higher rates of preterm delivery, perineal lacerations, and postpartum hemorrhage. ${ }^{4}$ Vascular type EDS has the potential for severe morbidity and mortality owing to these patients' propensity to vascular and visceral tissue fragility. ${ }^{5}$ Mode of delivery and type of anesthesia remain controversial, and little guidance exists as to how best to counsel and manage a parturient with a conflicting genetic and clinical picture.
We describe a case of a parturient clinically diagnosed with hypermobility type EDS prior to pregnancy but found to have a variant of unknown significance in the COL3AI gene causative for vascular type EDS. This situation posed a unique challenge as regards assisting in the anesthetic management of her labour in the midst of this conflicting genetic and clinical picture. We received patient consent for publication of this case report.

\section{Case report}

A 26-yr-old primigravida in her $39^{\text {th }}$ week of gestation was referred to the Obstetrical Anesthesia consult service by our Maternal Fetal Medicine inpatient service. She was diagnosed with hypermobility type EDS two years prior to her pregnancy after she presented with concerns of joint pain and hypermobility primarily in her shoulders and knees. Her Beighton score, a common physical examination tool for evaluation of hypermobility, was 9/ $9 ;^{1}$ however, she did not undergo genetic testing at that time. Review of her medical history did not reveal any evidence of typical EDS complications, such as skin thinness or fragility, poor wound healing or wide atrophic scarring, vascular friability and bleeding, or major vessel and hollow viscous dysfunction. Her family history did not reveal any formal diagnosis of EDS, but her mother and a maternal aunt were identified as having similar manifestations of joint hypermobility. She had an otherwise relatively unremarkable medical history and had received uncomplicated general anesthetics for minor surgical procedures in the past. Because of this reassuring medical history, genetic testing was not deemed urgent and was performed only in the third trimester of pregnancy to rule out a diagnosis of vascular EDS. The testing instead identified a genetic change/variant in the COL3Al gene associated with vascular type EDS but of uncertain biological significance for which she was heterozygous. In particular, this variant represented an amino acid change from lysine to arginine in the C-terminal domain in exon 50 of the COL3A1 gene. The common pathogenic changes for collagen proteins are typically in the glycine backbone, which was not the case with this patient. ${ }^{3}$ Although she had been clinically diagnosed with hypermobility type EDS and displayed phenotypic characteristics consistent with this disease subtype, her genetic variant was possibly consistent with the vascular subtype. Transthoracic echocardiography results did not reveal any cardiovascular abnormality.

We were asked to be involved in the care of this patient upon her admission to the high-risk antepartum unit for a planned induced labour. An induced labour with 


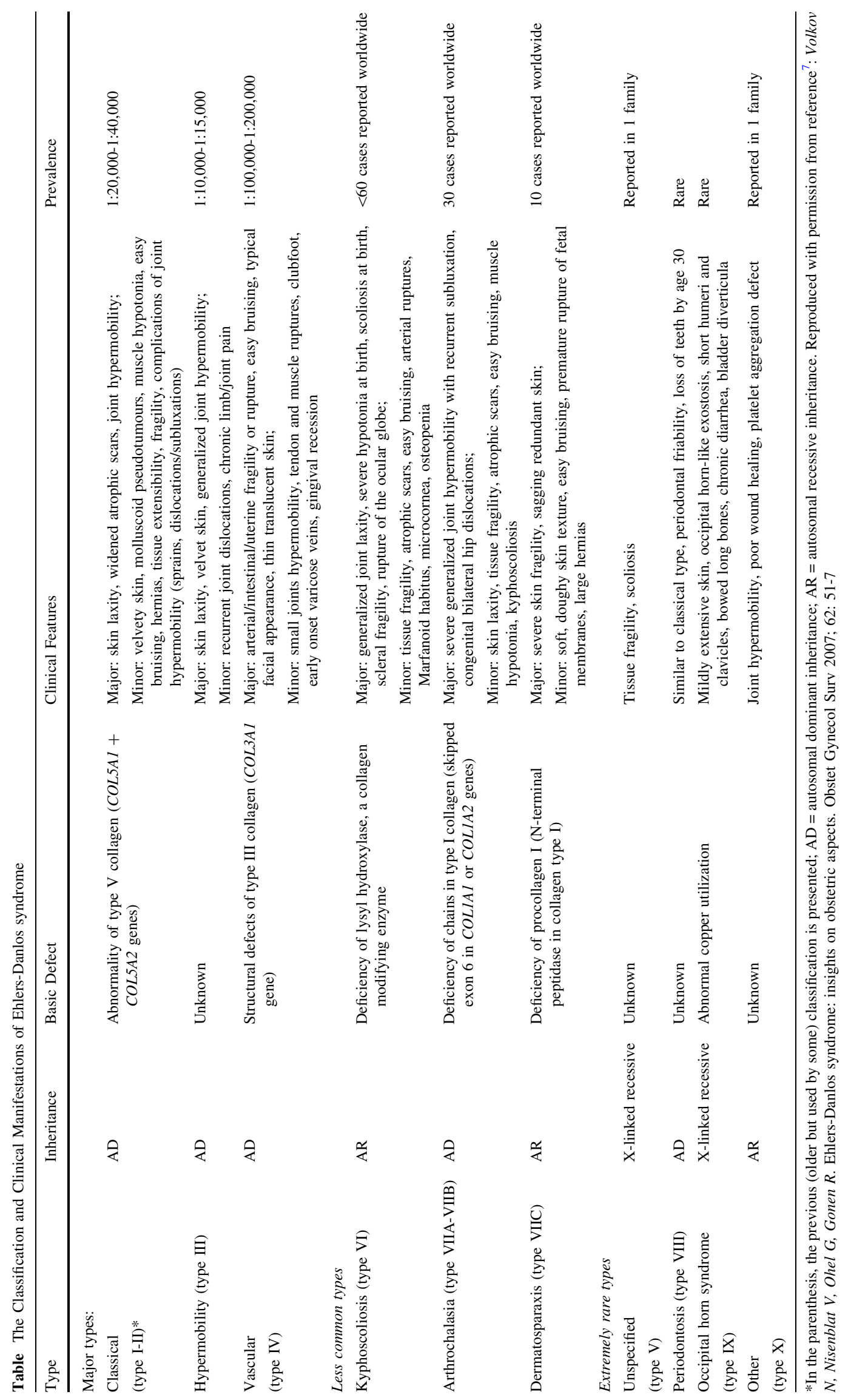


instrumental delivery was planned to facilitate a shortened second stage. As this patient would inevitably require dense sensory blockade for the instrumented delivery, we elected to place an epidural catheter for provision of labour analgesia and anesthesia during delivery. After disclosing the potential risks of the procedure and receiving the patient's informed consent, an epidural was placed at L3L4. After a negative test dose ( $2 \%$ lidocaine $3 \mathrm{~mL})$, a loading dose of $0.125 \%$ bupivacaine $10 \mathrm{~mL}$ with fentanyl $50 \mu \mathrm{g}$ was given. The patient subsequently received patient-controlled epidural anesthesia with $0.0625 \%$ bupivacaine with fentanyl $2 \mu \mathrm{g} \cdot \mathrm{mL}^{-1}$ (bolus, $5 \mathrm{~mL}$; lockout interval, ten minutes; continuous infusion, 10 $\mathrm{mL} \cdot \mathrm{hr}^{-1}$; maximum $20 \mathrm{~mL} \cdot \mathrm{hr}^{-1}$ ) and eventually a top up with $2 \%$ lidocaine $10 \mathrm{~mL}$ for forceps delivery. The delivery and both maternal and neonatal outcomes were uneventful.

\section{Discussion}

This case report highlights the importance of consideration of both phenotype and genotype in the risk assessment and management of a pregnant woman with EDS.

Ehlers-Danlos syndrome is characterized by a spectrum of heritable connective tissue disorders that can affect the skin, ligaments, joints, blood vessels, and internal organs. ${ }^{6}$ The six major subtypes in the Villefranche classification system differ based on phenotypic presentation, but they are largely under the umbrella of a group of mutations affecting collagen proteins or the enzymes involved in their production and modification. ${ }^{5}$ The type of collagen that is affected will produce a typical phenotypic syndrome with an expected pattern of tissue involvement and clinical presentation. Each respective syndrome has its own diagnostic criteria. Classical EDS is the most common subtype and is generally characterized by skin laxity, joint hypermobility, and widened atrophic scars. ${ }^{7}$ Hypermobility type EDS is characterized by skin laxity, velvet skin, and joint hypermobility. ${ }^{7}$ Vascular type EDS is characterized by typical facies, thin translucent skin that easily bruises, and the risk of arterial and hollow viscous rupture. Major and minor criteria used in the diagnosis of these conditions and a comprehensive list of EDS subtypes and their clinical features are listed in the Table. ${ }^{7}$

Vascular EDS is caused by a mutation in the COL3AI gene that codes for type III collagen; it has a prevalence of about $1 / 90,000$, but this estimate is likely low. ${ }^{8}$ It is an autosomal dominant disorder with $50 \%$ of mutations transmitted parentally and $50 \%$ being de novo mutations. ${ }^{9}$ Depending on the type of genetic mutation, phenotypic presentation can range from no symptoms to those with severe vascular problems and early mortality. ${ }^{6}$ Affected patients typically present in late adolescence, and the median survival is $48 \mathrm{yr}^{2,10}$ Vascular events do not usually occur in the newborn period or childhood. ${ }^{10}$ When compared with the other subtypes of EDS, the vascular type has largely been recognized as having the worst prognosis due to vessel/organ rupture and its associated early mortality. ${ }^{6,11}$ Vascular fragility can lead to disproportionate bleeding and bruising and is often an early presenting feature. ${ }^{6}$ Due to the risk of bleeding and hematoma formation, elective surgical interventions of any type are discouraged if an alternative conservative measure is available.

Pregnancy in the setting of EDS can be especially challenging. While hypermobility type EDS carries a relatively benign course and poses little added risk in pregnancy, mortality rates in parturients with vascular EDS have been estimated at $12-25 \% .^{9}$ Labour, delivery, and the postpartum period carry the highest risk. ${ }^{8}$ Risks associated with vaginal delivery in vascular EDS include bowel and/ or uterine rupture, extensive perineal trauma, and severe bleeding. ${ }^{5}$ Risks associated with Cesarean delivery include bleeding, visceral injury, and delayed wound healing. Both delivery modes carry specific risks associated with the choice of anesthetic technique. ${ }^{5}$ Current literature regarding the most appropriate method of delivery and provision of anesthesia in EDS is sparse and generally limited to case reports. Overall, recommendations against the provision of neuraxial anesthesia in vascular type EDS have been made in light of the theoretical risk of spinal hematoma formation. ${ }^{3,5,12}$ Some have also recommended early delivery at 32-34 weeks gestational age via Cesarean delivery under general anesthesia. ${ }^{13}$

Given the above discussion, we considered our patient to be in a very unique clinical situation - i.e., if we managed her condition based on the considerations of her hypermobility phenotype, we might put her at risk of potential complications from her potentially significant vascular genotype. Due to the high risk of morbidity and mortality, previous case reports have highlighted the concept of presymptomatic testing as regards asymptomatic patients with a positive family history of vascular EDS. In a case report described by Naing et al., ${ }^{9}$ the decision to recommend a normal course of labour for a pregnant woman with a family history of vascular EDS was dependent on the results of her presymptomatic genetic testing. The parturient in this case was in fact negative for vascular EDS, allowing the healthcare providers to recommend a term vaginal delivery as opposed to a Cesarean delivery earlier in her pregnancy. Although not specific to vascular type EDS during pregnancy, another case report has documented the uneventful nephrectomy and carotid revascularization of a patient who had a genetically positive vascular type EDS diagnosis but little evidence of clinical disease. ${ }^{11}$ It is with this rationale that we proceeded with decision-making pertaining to our 
patient's reassuring clinical features rather than her uncertain genetic finding.

As gene mutation analyses continue to progress and become more refined, novel mutations are continuously being identified, even prompting the suggestion that further subtypes of EDS need to be defined. ${ }^{13}$ Certain COL3A1 heterozygous null mutations have been identified that appear to have reduced penetrance with a less severe phenotype. ${ }^{14}$ Our patient's variant did not fall into a described genetic category, which left us unable to draw definitive conclusions about her phenotype; however, it does appear that her clinical course was not typical of vascular EDS. The biological significance of her variant remains unknown, as it differs from pathogenic mutations that typically occur in the glycine backbone of collagen proteins. The genetics team involved during her admission agreed with the clinical diagnosis of hypermobility type EDS and suspected that this alteration may be a benign familial variant or that this variant may be significantly less deleterious. Thus, the previously noted recommendations for the management of the parturient with vascular type EDS did not seem particularly relevant in this rare situation.

In summary, this case highlights the importance of a multidisciplinary approach to peripartum decision-making in the setting of EDS. Further research regarding such rare variants and their clinical significance is required in order to make definitive clinical recommendations. Clinical assessment of the patient, family history, and patient age at the time of clinical presentation of vascular EDS should also be considered when making clinical decisions. Overall, genetic testing of patients who display features of EDS and/ or who have a positive family history of the disease is important in the preparation for labour and delivery due to the potential for catastrophic complications. Nevertheless, in the absence of family history and convincing phenotypic signs of vascular EDS, it may be rational, after informed consent, to offer neuraxial anesthesia and a trial of vaginal labour to certain asymptomatic parturients.

\section{Funding None.}

Conflicts of interest None declared.

\section{References}

1. Beighton P, De Paepe A, Steinmann B, Tsipouras P, Wenstrup $R J$. Ehlers-Danlos syndromes: revised nosology, Villefranche, 1997. Ehlers-Danlos National Foundation (USA) and EhlersDanlos Support Group (UK). Am J Med Genet 1998; 77: 31-7.

2. Gilchrist D, Schwarze U, Shields K, MacLaren L, Bridge PJ, Byers $P H$. Large kindred with Ehlers-Danlos Syndrome type IV due to a point mutation (G571S) in the COL3A1 gene of type III procollagen: low risk of pregnancy complications and unexpected longevity in some affected relatives. Am J Med Genet 1999; 82: 305-11.

3. Narcisi P, Richards AJ, Ferguson SD, Pope FM. A family with Ehlers-Danlos syndrome type III/articular hypermobility syndrome has a glycine 637 to serine substitution in type III collagen. Hum Mol Genet 1994; 3: 1617-20.

4. Palmquist M, Pappas JG, Petrikovsky B, Blakemore K, Roshan $D$. Successful pregnancy outcome in Ehlers-Danlos syndrome, vascular type. J Matern Fetal Neonatal Med 2009; 22: 924-7.

5. Wiesmann T, Castori M, Malfait $F$, Wulf $H$. Recommendations for anesthesia and perioperative management in patients with Ehlers-Danlos syndrome(s). Orphanet J Rare Dis 2014; 9: 109.

6. De Paepe A, Malfait $F$. The Ehlers-Danlos syndrome, a disorder with many faces. Clin Genet 2012; 82: 1-11.

7. Volkov $N$, Nisenblat $V$, Ohel $G$, Gonen $R$. Ehlers-Danlos syndrome: insights on obstetric aspects. Obstet Gynecol Surv 2007; 62: 51-7.

8. Pepin MG, Schwarze U, Rice KM, Liu M, Leistritz D, Byers PH. Survival is affected by mutation type and molecular mechanism in vascular Ehlers-Danlos syndrome (EDS type IV). Genet Med 2014; 16: 881-8.

9. Naing BT, Watanabe A, Tanigaki S, Ono M, Iwashita M, Shimada $T$. Presymptomatic genetic analysis during pregnancy for vascular type Ehlers-Danlos syndrome. Int Med Case Rep J 2014; 7: 99-102.

10. Pepin M, Schwarze U, Superti-Furga A, Byers PH. Clinical and genetic features of Ehlers-Danlos syndrome type IV, the vascular type. N Engl J Med 2000; 342: 673-80.

11. Dwivedi AJ, Hamdallah O, Morris ME, Yancey AE, Ross CB. Varying presentations in patients with symptomatic type IV vascular Ehlers-Danlos syndrome. Vasc Endovascular Surg 2012; 46: 163-6.

12. Kuczkowski KM. Ehlers-Danlos syndrome in the parturient: an uncommon disorder-common dilemma in the delivery room. Arch Gynecol Obstet 2005; 273: 60-2.

13. Bagou G, Frank M. Type IV Ehlers - Danlos Syndrome. Available from URL: https://www.orpha.net/data/patho/Pro/en/ Emergency_Ehlers-DanlosTypeIV-enPro4042.pdf (accessed August 2015).

14. Hammond R, Oligbo $N$. Ehlers Danlos syndrome type IV and pregnancy. Arch Gynecol Obstet 2012; 285: 51-4. 